\title{
A AQUISIÇÃO DA LEITURA POR ALUNOS DA EJA/ENSINO MÉDIO EM CONTEXTOS POPULARES
}

\author{
joão Paulo da Concelção Alves \\ Carla lorena Rodrigues de Carvalho \\ Márcia Pereira da Silva \\ Universidade Federal do Amapá (UNIFAP), Macapá, Amapá, Brasil
}

Resumo: A presente pesquisa busca abordar formas de aquisição da leitura em espaços periféricos como estratégia para a formação humana na Educação de Jovens e Adultos (EJA). Este trabalho tem como objetivo geral analisar formas de aquisição da leitura na realidade de alunos da EJA/Ensino Médio na cidade de Macapá - AP. Utilizaremos as abordagens qualitativa e quantitativa, além de gráficos, com a aplicação de questionários para 23 alunos. Concluímos que a maioria dos alunos não reconhece os espaços de leitura como biblioteca comunitária, tampouco a prática da leitura como instrumento de formação educacional/humana, divorciando a aquisição da leitura da ressignificação da realidade das pessoas e da comunidade.

Palavras-chave: Biblioteca comunitária. Prática de leitura. Educação de jovens e adultos. Ensino Médio.

\section{INTRODUÇÃO}

A pesquisa intitulada "Formas de aquisição da leitura de alunos da EJA/Ensino Médio em espaços periféricos da cidade de Macapá/Ap" surgiu da necessidade de verificar as possíveis perspectivas que os alunos do Ensino Médio da EJA, matriculados em uma escola de Ensino Médio, no 
bairro Pedrinhas, têm sobre os espaços na comunidade que potencialmente favoreçam a aquisição da leitura.

Sobre o processo de leitura e escrita, o concebemos sob uma perspectiva dialética da realidade como concepção e ruptura e como mediação dos processos históricos. A escrita/leitura aqui é tratada como atividade (no nosso caso, de conceituar/teorizar), como ação de apropriação da realidade em sua dupla dimensão: interpretação e produção (JANTSCH, 2002).

Mediante a análise quanto ao processo de apropriação da leitura por parte dos sujeitos, a Educação de Jovens e Adultos (EJA) figura como modalidade de ensino objeto de nossas análises pelo seu caráter socialmente contraditório, voltada a um público que apresenta um histórico sociocultural de exclusão e de limitação do seu direito ao ensino regular, por diversos fatores.

Falamos da EJA com ênfase nas dificuldades decorrentes do (re) ingresso ao sistema educacional, pois há muitos estigmas e preconceitos que o envolvem, tanto dentro como fora da escola. Partindo dessa peculiaridade dos educandos da EJA, é importante que não somente o professor perceba o potencial de cada aluno, mas também a sociedade empenhe esforços para que esses alunos sejam capazes de mudar significativamente sua vida, alcançando melhores condições profissionais e pessoais.

É diante deste cenário pautado na realidade concreta que propomos a análise sobre as formas de aquisição da leitura de alunos da EJA/Ensino Médio em espaços periféricos da cidade de Macapá - AP. A Unidade de Polícia Comunitária - UPC Araxá/Pedrinhas é aqui entendida como um espaço potencialmente privilegiado que, somado às práticas pedagógicas das escolas que desenvolvem o ensino na modalidade EJA nos bairros Araxá e Pedrinhas, pode contribuir como apoio educacional e como ambiente de atendimento aos alunos das referidas escolas através das atividades disponibilizadas pela UPC, conforme discorrido em seção posterior, com ênfase à Biblioteca Comunitária da UPC.

Este trabalho tem o objetivo, portanto, de analisar formas de aquisição da leitura na realidade de alunos da EJA/Ensino Médio em espaços periféricos da cidade de Macapá - AP, particularmente na região que engloba os bairros Pedrinhas e Araxá. Partimos nesta pesquisa da necessidade de compreender a construção social da leitura e da escrita. Para tanto, utilizamos Kosik (1976) na análise do fenômeno como algo real, na sua essência e unidade e, portanto, sob a realidade concreta.

Como instrumento para coleta de dados, utilizamos Thiollent (1981), pois compreendemos que a observação qualitativa e quantitativa, com 
aplicação de questionários e coleta de dados para análise do conteúdo, é a que melhor se adequa a este tipo de estudo.

As etapas da coleta de dados se deram da seguinte forma: primeiramente foi desenvolvida uma pesquisa bibliográfica e documental, da qual foi possível nos apropriarmos das bases teóricas da Educação de Jovens e Adultos. Para tanto, foram utilizados autores como Gramsci, Jantsch, Freire, Rummert e Cachapuz, como forma de analisar as transformações na realidade material e/ou no mundo do trabalho. Além desses autores, foram estudadas diversas legislações que versam sobre a EJA, como a Lei Federal no 9.394/96, que trata da organização da Educação Nacional.

Na pesquisa empírica, foram entregues, no total das duas turmas, 36 questionários, sendo recolhidos 23 respondidos, 1 rasurado e 9 devolvidos em branco, além de 3 não devolvidos. Desta forma, de acordo com o Gráfico 1, obtivemos $26 \%$ de participação dos alunos da Turma 1 e $74 \%$ de participação dos alunos da Turma 2.

Para a elaboração deste trabalho de forma compreensível, ele foi dividido em seis seções, a saber, a Introdução; Reflexões sobre a Educação de Jovens e Adultos no Brasil; A condição social dos alunos na construção do seu processo educativo; As práticas de leitura evidenciadas na vida do aluno; As perspectivas dos alunos do Ensino Médio/EJA sobre a função educativa das bibliotecas para a prática de leitura e escrita, e as Considerações finais.

\section{Reflexões sobre a Educação de Jovens e Adultos no Brasil}

Ao fazermos algumas reflexões sobre a Educação de Jovens e Adultos em um sentido amplo, é necessário analisar historicamente a política educacional no Brasil, de modo a entender o grande contingente de pessoas excluídas do processo educacional. Historicamente, o Brasil desenvolveu uma educação fragmentada e desigual, a qual se aprofunda para jovens e adultos.

Em corroboração a essa ideia, autores como Haddad e Di Pierro (2000) e Freire (1987) nos remetem à necessidade da educação por uma perspectiva de "reinvenção" da sociedade, na qual o ser humano assuma o papel de sujeito histórico, transformador do mundo em que vive, libertando-se da "cultura do silêncio" no qual se encontra imerso. Cachapuz (1999) considera que, numa educação para a cidadania, deve-se ir além dos objetivos centrados nos conteúdos, pois os temas/problemas sociais extraídos do "mundo vivido"'carregam", para o "mundo da escola", a complexidade do mundo real, contribuindo para a compreensão e a busca de soluções para problemas reais.

Entendemos ainda que mudanças curriculares, mediante o enfoque temático que seja dado às ações, contribuem para a superação 
da fragmentação e apontam para uma perspectiva que supere o dualismo e o e a exclusão.

Observamos que o artigo 37, da Lei Federal no 9.394/96, que estabelece as Diretrizes e Bases da Educação Nacional (LDB), define que "a educação de jovens e adultos será destinada àqueles que não tiveram acesso ou continuidade de estudos no ensino fundamental e médio na idade própria". $\mathrm{O} \S 1^{\circ}$ do mesmo artigo determina que os Sistemas de Ensino assegurem a esses jovens e adultos, gratuitamente, "oportunidades educacionais apropriadas, consideradas as características do alunado, seus interesses, condições de vida e de trabalho". Essas oportunidades educacionais, de acordo com o artigo 38 da LDB, devem compreender "a Base Nacional Comum do currículo, habilitando ao prosseguimento de estudos em caráter regular" (BRASIL, 1996).

Segundo Freire (1987), a Educação de Adultos viveu um processo de amadurecimento que veio transformando a compreensão que dela tínhamos poucos anos atrás. Assim, o conceito de Educação de Adultos passou a se mover em direção ao de Educação Popular, pois:

Não é possível a educadoras e educadores pensar apenas os procedimentos didáticos e os conteúdos a serem ensinados aos grupos populares. Os próprios conteúdos a serem ensinados não podem ser totalmente estranhos àquela cotidianidade. $\mathrm{O}$ que acontece, no meio popular, nas periferias das cidades, nos campos - trabalhadores urbanos e rurais reunindo-se para rezar ou para discutir seus direitos (FREIRE apud ROMÃO; GADOTTI, 2007, p. 15-16).

Verificou-se ainda, através de dados do site do Fórum Mineiro de Educação de Jovens e Adultos, que, em termos de Brasil, conforme dados do Censo 2010, dentre as pessoas com 15 anos ou mais de idade, 14,6 milhões são analfabetas e cerca de 45 milhões não concluíram a Educação Básica. Ao todo, são aproximadamente 60 milhões de brasileiros que não tiveram assegurado o seu direito constitucional à educação. Entre os jovens de 18 a 24 anos, 36,5\% haviam interrompido o estudo antes de completar o Ensino Médio, em 2010. Destes, a maioria (52,9\%) deixou a escola antes de terminar o Ensino Fundamental, enquanto 21,2\% interromperam o percurso escolar logo após ingressar no Ensino Médio. Esta é uma modalidade constituída por jovens, adultos e idosos aos quais o direito à educação vem sendo sistematicamente negado.

Arroyo (2011) nos aponta um balanço sobre os anos anteriores da EJA, verificando que seus currículos não foram pensados para a situação de instabilidade que ainda perdura em nosso país. Demostra, por outro lado, que a flexibilização nos currículos da EJA seria uma forma de atender esses 
jovens e adultos que não conseguiram estudar no período do ensino regular e hoje vivem na informalidade, inseguros sobre sua vida.

Ciavatta e Rummert (2010) nos mostram reflexões que concorrem para a construção de propostas curriculares voltadas, especificamente, para a EJA, que rompam com os parâmetros utilizados, colocando uma proposta de formação integrada entre os princípios gerais e as ações específicas de educação profissional, tendo como eixo a ciência, a cultura e, portanto, o trabalho.

Nesse mesmo contexto, Rummert (2007) afirma que o campo da educação é fortemente marcado por condicionantes estruturais e que as ações de governo constituem expressão dos processos de correlação de forças, nos quais a modalidade de ensino conhecida como EJA constitui uma das mais claras expressões da dualidade característica do sistema educacional brasileiro, distribuindo de forma profundamente desigual as condições de acesso às bases do conhecimento.

Rummert (2008) observa ainda que nos últimos anos, principalmente a partir de 2003, verificou-se uma ampliação da oferta de programas para a EJA (básica e profissional) como uma forma de democratização do que a autora chama de "simulacros de educação", mas que de fato não conseguem suprir as demandas e necessidades desses jovens e adultos trabalhadores do Brasil atual, onde os chamados "novos movimentos sociais" conseguem compreender melhor as necessidades da EJA.

\section{A CONDIÇÃO SOCIAL DOS ALUNOS NA CONSTRUÇÃO DO SEU PROCESSO EDUCATIVO}

Ao partir a campo, verificamos, conforme a tabela abaixo, que $48 \%$ dos alunos desta pesquisa estão na faixa etária de 22 a 25 anos, 35\% de 18 a 21 anos, $9 \%$ de 30 a 33 anos e $8 \%$ de 26 a 29 anos, sendo que não havia nenhum aluno com mais de 33 anos. Percebeu-se que o número de alunos na faixa etária até 25 anos ocupa mais de $80 \%$ do percentual pesquisado, estando esse fato relacionado ao momento em que o jovem busca recuperar o tempo perdido na escola.

Trata-se de um públco na EJA formado majoritariamente por jovens. Observamos que a condição social dos alunos que frequentam a EJA na escola estudada é de jovens que tiveram de abandonar a escola por motivo de trabalho, horários incompatíveis com a escola e que estão retornando aos estudos. Confirmamos a assertiva quando questionamos os alunos sobre as razões que os levaram a optar pela modalidade da Educação de Jovens e Adultos para concluírem o Ensino Médio (Aluno I).

Como resposta a este questionamento, verificamos, conforme pode-se ver abaixo, que 32\% optaram pela EJA por ser um "ensino rápido", 
concluído em dois anos, o que nos revela o sentido utilitário da modalidade EJA; enquanto $27 \%$ optaram pela EJA por estarem em atraso nos estudos, $9 \%$ em função do trabalho que realizam, $5 \%$ para ter um melhor conhecimento, $5 \%$ para entrar na faculdade, $4 \%$ por ter abandonado os estudos, $4 \%$ em função da idade e do horário e $14 \%$ por outros motivos (como trabalhar e cuidar dos filhos ou para poderem entrar no mercado de trabalho). Observe o gráfico abaixo:

Gráfico 1 - Porcentagem obtida em resposta à pergunta sobre as razões que levaram o aluno a optar pela modalidade da EJA

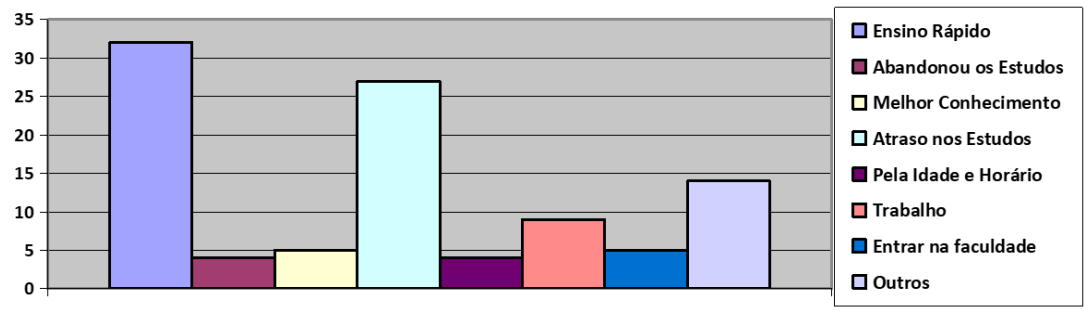

Fonte: Elaborado pelos autores (2016).

Desta forma, observamos que os alunos retornam à escola por necessidade de concluir seus estudos de uma forma rápida. Apesar da busca por novos conhecimentos, o utilitarismo, aliado à busca por melhor qualidade de vida, sobressai-se nesta análise. Pode também estender-se para a pretensão de inserir-se no ensino superior. A EJA é compreendida sob um cenário de repulsa, afastamento e perda de esperança, além de nos advertir para a necessidade de sua reestruturação para que oportunize aos jovens uma educação com qualidade social.

A Educação de Jovens e Adultos (EJA), regulamentada como modalidade de ensino, constitui-se uma educação para o subatendimento a uma determinada classe. Assim, se configura, no Brasil, como oferta de possibilidades de elevação da escolaridade para aqueles aos quais foi negado o direito à educação na fase da vida historicamente considerada adequada. É, mais precisamente, uma educação para as frações da classe trabalhadora cujos papéis a serem desempenhados no cenário produtivo não requerem maiores investimentos do Estado, enquanto representante prioritário dos interesses dos proprietários dos meios de produção (RUMMERT, 2007)

Confirmamos a assertiva acima quando analisamos a condição social dos alunos sob o viés da necessidade do trabalho como forma de subsistência, em confronto com a formação educacional. Quando 
questionados, portanto, se realizavam outra atividade além das atividades escolares, observou-se, conforme pode-se notar abaixo, que um terço dos alunos entrevistados trabalha.

Gráfico 2 - Porcentagem de respostas sobre atividades diversas realizadas pelos alunos, para além das escolares
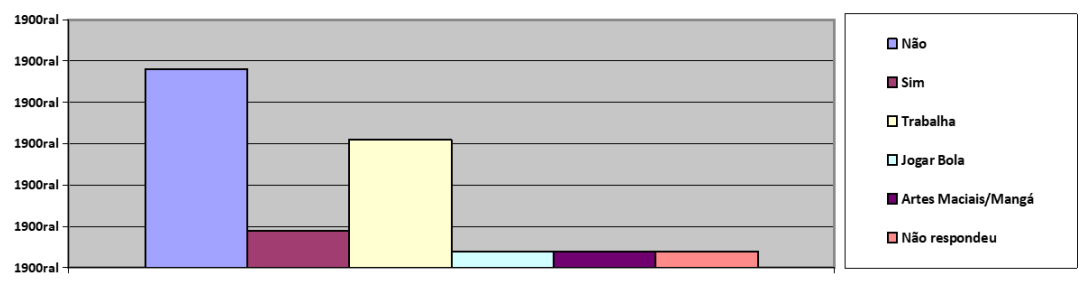

Fonte: Elaborado pelos autores (2016).

De acordo com o Gráfico 2, destacamos que cerca de $30 \%$ dos alunos têm o trabalho como atividade principal, inclusive por necessidade de subsistência familiar, expondo uma dupla face negativa: a inserção precoce e desqualificada no mercado de trabalho e a matrícula na EJA diante de todos os problemas nessa modalidade de ensino, já apontados pelos índices oficiais.

Outro destaque diz respeito ao fato de que cerca de $40 \%$ desses alunos apenas estudam e que a escola não tem se mostrado como alternativa para a melhoria de vida dessas pessoas. Esta constatação pode ser confirmada mediante os dados oficiais do INEP, os quais apresentam índices de abandono bastante elevados. No ano de 2012, por exemplo, o estado do Amapá apresentou taxa de abandono de 14,5\%, ficando atrás apenas do Pará (17,7\%). Esses dados constituem reflexos da realidade amazônica (ANGÉLICO, 2012).

O fato de a maioria dos alunos não realizarem atividade alguma, além das atividades escolares, nos apresenta com nitidez o fenômeno do desemprego no estado do Amapá e a consequente ociosidade da juventude, como contribuinte para o aumento das taxas de violência. Neste caso, observamos que os dados oficiais sobre os índices de homicídios no estado do Amapá têm aumentado nos últimos anos em comparação com a realidade nacional; por exemplo, enquanto no Brasil, na variação dos anos de 2004 e 2014, registrou-se um aumento de 16,4\%, no Amapá esse índice foi praticamente o dobro, ficando em 31,4\%.

A maioria dos alunos entrevistados também afirmou que apenas no turno da noite dispõe de tempo disponível para realizar suas atividades extraescolares (realização de leituras, trabalhos cobrados em sala de aula), ou seja, no mesmo horário em que deveriam estar ou estão em aula. A relação 
que esses alunos estabelecem com a educação e com o trabalho se constrói de forma precária e subsumida pela necessidade de subsistência.

Rummert (2007) analisa que o caráter de educação com "status" inferior no mercado de bens culturais, conferido à Educação de Jovens e Adultos, está também evidenciado na Lei de Diretrizes e Bases da Educação Nacional, no 9.394, de 1996.

\section{As PRÁtICAS DE LEITURA EVIDENCIADAS NA VIDA DO ALUNO}

A apropriação da fala e da escrita constitui elemento fundamental para o amplo desenvolvimento das potencialidades humanas. Partimos da compreensão de que a escrita assume uma concepção dialética da realidade, pois consiste em uma apropriação do real, de modo a estabelecer sínteses que abarcam o real, ao mesmo tempo interpretando e produzindo o real; portanto, não basta apenas descrever (JANTSCH, 2002).

Partindo deste pressuposto, buscamos conhecer quais as leituras que os alunos, sujeitos da pesquisa, fazem no cotidiano, para assim entendermos a forma de sua apropriação. Percebemos, conforme se pode observar abaixo, que a maioria costuma ler textos de redes sociais, como WhatsApp e Facebook, num total de $44 \%$. Verificou-se também que $25 \%$ costumam fazer leituras indicadas pelos professores, $7 \%$ realizam leituras de revistas e jornais impressos, $7 \%$ de revistas e jornais em mídia e 7\% de livros de contos ou poemas e ainda 10\% fazem outros tipos de leituras como a Bíblia, animes e quadrinhos.

Gráfico 3 - Tipos de leitura que o aluno costuma fazer em seu dia a dia
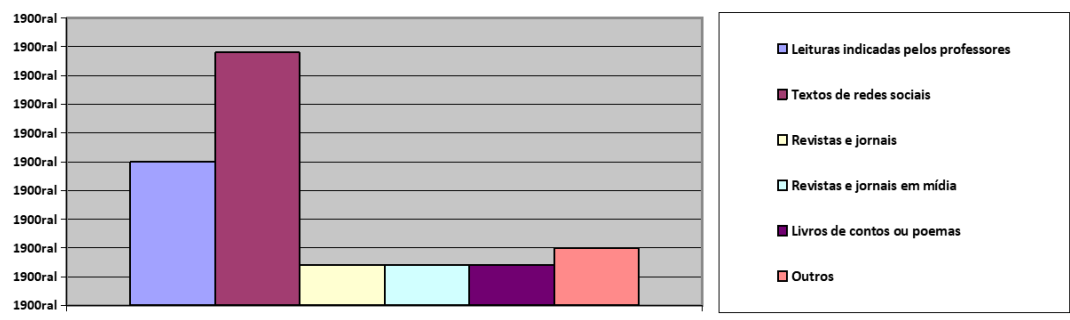

Fonte: Elaborado pelos autores (2016).

Silva (2015) contribui para a compreensão dos dados obtidos, quando diz que:

Estima-se que $48 \%$ dos jovens entre 16 e 25 anos utilizem a internet todos os dias por aproximadamente 4 horas (BRASIL, 2014). Tal fato coexiste com o 
aparente declínio da leitura de livros revelado pela pesquisa Retratos da Leitura no Brasil, com a média anual de livros lidos por jovens entre 18 e 24 anos caindo de 4.4, em 2007, para 3,9 em 2011 (FAILLA, 2012). Ambas informações derivam de um panorama geral sobre hábitos de consumo de mídia e práticas de leitura no país, respectivamente, mas despertam questionamentos cujas respostas possivelmente residem na realidade local de pequenos grupos. Ao analisarmos essas duas medições paralelamente, encontramos pistas de que a leitura de livros não é uma prática em ascensão entre esta faixa etária, ao contrário do uso de mídias sociais, como o Facebook, que cresce conforme se expande o acesso à internet (SILVA, 2015, p.89).

Desta forma, verifica-se que, independente do seu grau de escolaridade ou poder aquisitivo, o uso da internet como forma de leitura é algo bastante presente, entretanto, nessa leitura, por ser despropositada e despolitizada, a apreensão de mundo na maioria dos casos não é efetivada de fato. A utilização de espaços diversos para a realização da aprendizagem pode ser complementado ainda por Silva e Rodrigues (2010), que assinalam que os Parâmetros Curriculares Nacionais enfatizam que a formação de leitores e a prática de leitura não devem se restringir apenas aos recursos materiais disponíveis, mas ao uso de demais espaços, como, no caso, a utilização das bibliotecas comunitárias e dos recursos dela decorrentes.

Ainda sobre este tema, os alunos foram questionados se consideravamse leitores e se gostariam de ter mais práticas de leitura ou consideravam ler o suficiente para as atividades cotidianas, sendo verificado que $24 \%$ dos alunos se consideram leitores, seguidos de $20 \%$ que gostariam de ter mais práticas de leitura e $16 \%$ que entendem ler o suficiente para as atividades cotidianas, desta forma observamos que $60 \%$ dos que responderam o questionário se consideram leitores. Em contrapartida, $20 \%$ dos alunos responderam que não se consideram leitores, $12 \%$ disseram apenas "Não", 4\% disseram não gostar de ler e outros $4 \%$ não responderam, conforme consta no gráfico abaixo.

Gráfico 4 - Prática de leitura realizada pelos alunos em atividades cotidianas
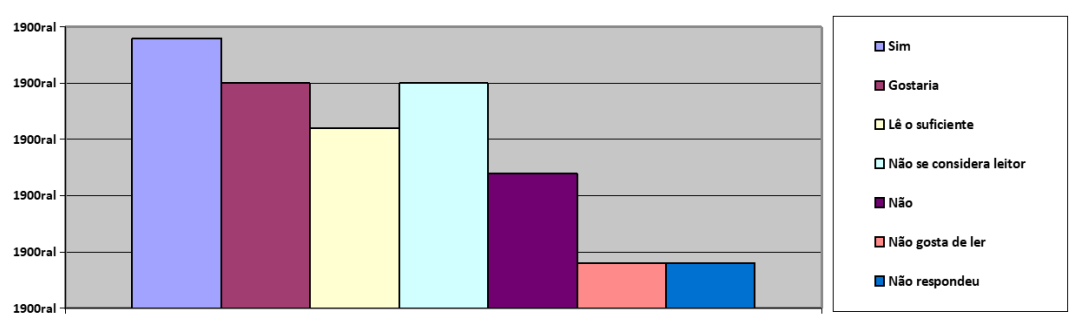

Fonte: Elaborado pelos autores (2016). 
Neste sentido, a apropriação da leitura é considerada pelos alunos como uma forma de ascensão social. Do mesmo modo que considerar-se leitor significa apropriar-se de uma visão de mundo autônoma, também podemos afirmar que a leitura/escrita é uma forma de abstração pela necessidade da elevação da reflexão (em comparação com a cópia, que praticamente não exige pensamento), apropriando-se da realidade, interpretando-a e produzindo-a.

\section{As PERSPECTIVAS dos ALUNOS do ENSINO MÉDIO/EJA SOBRE A FUnÇÃO EDUCATIVA DAS BIBLIOTECAS PARA A PRÁTICA DE LEITURA E ESCRITA}

Nesta seção, analisaremos a função educativa que uma biblioteca comunitária pode ter para a formação educacional dos alunos. Buscamos saber a princípio onde os entrevistados realizavam suas leituras e se frequentavam algum local específico para fazê-la. Como resposta, verificouse que $40 \%$ não costumam fazer leituras, $32 \%$ responderam que as fazem em casa, $4 \%$ na escola, $4 \%$ no trabalho, $4 \%$ em qualquer lugar, $4 \%$ em lan house, $4 \%$ responderam apenas que "Sim" e $8 \%$ não responderam, conforme o gráfico abaixo:

Gráfico 5 - Porcentagem obtida em resposta à pergunta sobre onde costuma realizar as leituras, e se frequenta algum local específico

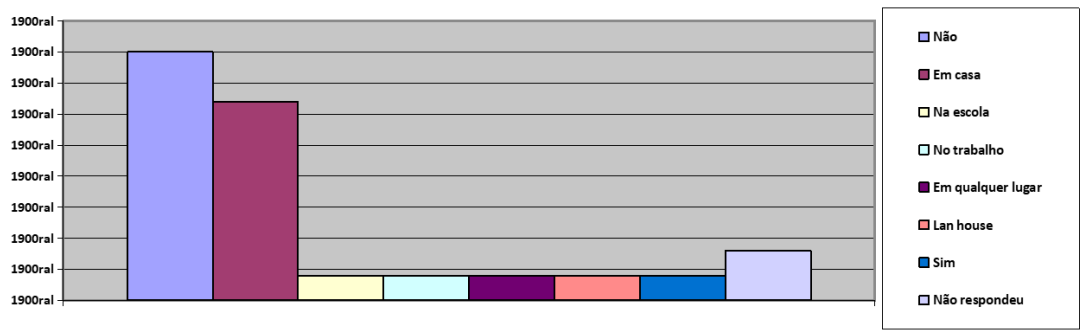

Fonte: Elaborado pelos autores (2016).

Estes dados demonstram que, mesmo com a quantidade abundante de informações, estas não fazem parte do cotidiano da maioria da população e isso é motivo de preocupação, pois, conforme os dados do Gráfico 5 , muitos alunos não realizam leituras com frequência, se mostrando alheios a esse mundo.

Coelho (2016) enfatiza que a questão de ir ao espaço da biblioteca é uma atividade que não faz parte do cotidiano da maioria das pessoas. Este 
fato foi identificado aos questionarmos sobre em quais situações os alunos costumavam frequentar a biblioteca da escola, conforme o Gráfico 6:

Gráfico 6 - Porcentagem obtida em resposta à pergunta sobre em quais situações os alunos frequentam a biblioteca da escola

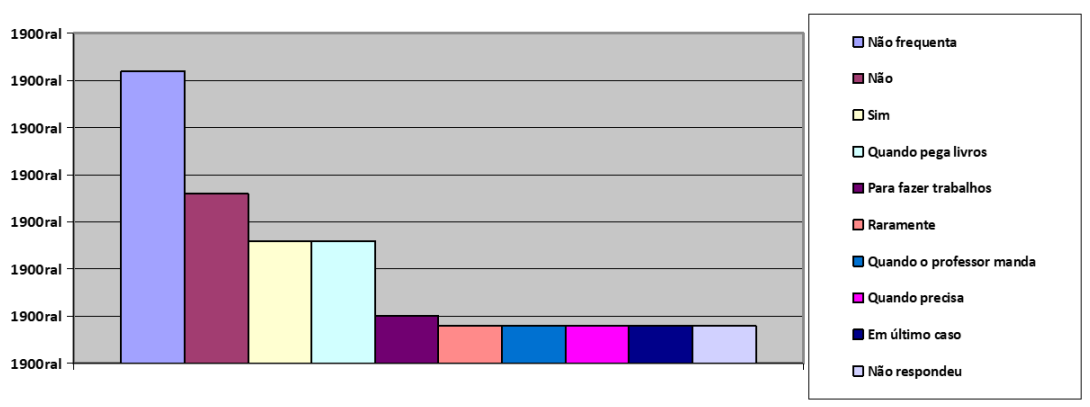

Fonte: Elaborado pelos autores (2016).

A frequência à biblioteca da escola constitui indicativo importante quanto à subutilização da biblioteca para a prática da leitura e escrita e para a formação de leitores, pois praticamente um terço dos alunos não a frequenta. Por outro lado, apenas $5 \%$ dos alunos afirmaram que frequentam a biblioteca para fazer alguma atividade escolar e, de uma forma mais sistemática, a utilizam para a construção do conhecimento.

A ausência de alunos da EJA na biblioteca pode ser relacionada ao conhecimento que se tem sobre a existência desses espaços de leitura nos arredores da escola. Sobre a pergunta referente ao conhecimento por parte dos alunos da Biblioteca da UPC, obtivemos como resposta que a maioria dos alunos não tinha conhecimento da existência de uma biblioteca na UPC: um total de $70 \%$ disse não conhecer a biblioteca, seguido de $26 \%$ que gostariam de conhecer e de $4 \%$ que deixaram esta pergunta em branco, conforme o Gráfico 7 abaixo. 
Gráfico 7 - Conhecimento dos alunos sobre a existência de biblioteca no bairro/ comunidade

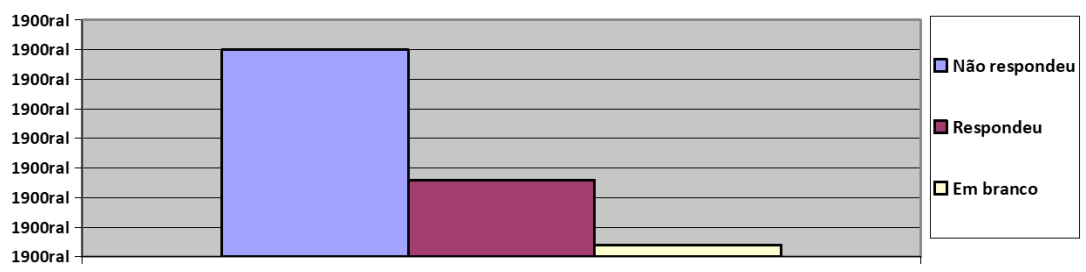

Fonte: Elaborado pelos autores (2016).

Embora a prática da leitura possa acontecer no cotidiano familiar e nas demais relações sociais dos sujeitos, esta constatação é preocupante, pois expõe a ausência de uma cultura de busca pela informação mediante a capacidade de abstração, construção e apropriação do conhecimento por meio da leitura.

Corroborando a necessidade de criação de círculos de leitura, observamos ainda em Gramsci (1989), sobre a questão das bibliotecas populares, que trata-se de uma "brilhante iniciativa em favor da cultura popular". Para esse mesmo autor, as bibliotecas fazem parte dos serviços públicos intelectuais, devendo estes ser assegurados pelo Estado e pelas entidades locais. Essa resposta nos remete ainda à pesquisa realizada por Coelho (2016), ao nos informar que esses dados mostram uma realidade preocupante: demonstram reflexos de experiências ruins durante a formação educacional ou o contato insuficiente para despertar esse interesse pela leitura e pelo uso de bibliotecas.

Neste contexto, enfatizamos que:

[...] as bibliotecas ainda são insipientes para contemplar as dimensões do país. De acordo com a última atualização realizada em 2015 o Brasil possuí 6.102 bibliotecas englobando as públicas municipais, distritais, estaduais e federais, nos 26 estados e no Distrito Federal (SISTEMA, 2016) número total que não contempla boa parte dos rincões do país, levando a brotar iniciativas de grupos insatisfeitos com o acesso oferecido pelas políticas públicas de informação e leitura como as bibliotecas comunitárias (COELHO, 2016, p. 419-420).

A maioria dos alunos apontou que frequenta a biblioteca para encontrar algum livro. Em contrapartida, um número expressivo de alunos informou que não gosta de ler livros e só iria à biblioteca da UPC se fosse obrigado, mostrando o fato de que, apesar de a leitura ser o principal meio 
para obter informação, o acesso a esse espaço é bastante comprometido não apenas pelo aluno apresentar historicamente um acesso à cultura acidentado, mas por aspectos de ordem social.

A cultura da leitura e de tê-la como necessidade para a emancipação dos sujeitos precisa avançar partindo principalmente da construção de política públicas educacionais que, dentre as demais atribuições, garantam espaços de cultura e formação humana para o conjunto da sociedade. Diante dessa assertiva, Gramsci (1989) já nos advertia quanto ao fato de a escola e outros serviços públicos não deverem ser deixados à iniciativa privada, mas sim assegurados pelo Estado como direito; é o caso do teatro, das bibliotecas, etc. Como não há tais estruturas, não é de se estranhar o fato de não conhecerem a biblioteca ou distintos espaços de formação cultural/humana.

\section{CONSIDERAÇÕES FINAIS}

Nesta pesquisa, objetivou-se analisar a aquisição da leitura na realidade de alunos da EJA/Ensino Médio em espaços periféricos da cidade de Macapá - AP. Como resultado, verificamos que, apesar de alguns alunos sequer terem conhecimento de uma biblioteca comunitária em seu bairro, a maioria destes se mostrou bastante interessada em conhecer um local a mais para realizar suas atividades de leitura.

Verificamos ainda, no decorrer desta pesquisa, que as ações sociais e educativas que as instituições promovem podem possibilitar cidadania aos sujeitos envolvidos, atuando efetivamente na base de combate às mazelas sociais, entendendo que há a necessidade de políticas públicas estruturais para a cidadania plena.

Pelo fato de ser uma área de risco social, verificou-se que as condições sociais de alunos de um bairro periférico interferem diretamente na qualidade de sua educação, pois, além de não terem acesso à gama de materiais que são utilizados na educação formal, devido à precariedade do ensino publico como um todo, o meio em que vivem interfere diretamente na qualidade do ensino oferecido a esses alunos, como a escassez de locais próprios para leitura, pesquisa e mesmo a falta de locais de lazer adequados.

Com a falta de políticas públicas educacionais e, por conseguinte, a ausência de espaços de leitura para os alunos da EJA, os alunos dessa modalidade sofrem mais do que os alunos do ensino regular. Para poderem ter uma educação de qualidade e que possa de fato mudar suas vidas, não basta apenas o esforço de gestores escolares e professores, mas sim a disponibilidade de recursos para que haja espaços específicos para essa modalidade de ensino. 
Assim, com base nos dados coletados durante a pesquisa, confirmouse a hipótese segundo a qual os alunos da EJA tiveram de abandonar os estudos em idade regular por diversas razões e que retornam ao ensino em função das exigências do mercado de trabalho, para poderem ingressar no ensino superior ou simplesmente com o intuito de concluir o ensino regular.

Confirmou-se ainda que há a compreensão dos alunos sobre a importância da leitura como necessidade para sua emancipação social. Conseguiu-se verificar também os desafios que a Biblioteca da UPC, objeto de investigação deste trabalho, tem, em vista de todo esse contexto desfavorável.

A Biblioteca da UPC pode se tornar um espaço de leitura também para os alunos da EJA, que buscam sua emancipação social e podem passar a ver nas bibliotecas comunitárias de seu bairro um local especifico para a prática de leitura. No entanto, são necessárias ações que aproximem e democratizem a relação entre a comunidade escolar, os organismos de segurança e a sociedade de uma forma geral.

Portanto, há pouco reconhecimento da biblioteca comunitária como espaço educativo. Tampouco a prática da leitura consegue exercer grande influência na ressignificação da sua realidade da comunidade, expondo uma relação pragmática na busca pela informação mediante a apropriação de conhecimentos.

As demais relações sociais dos sujeitos e a emersão das redes sociais virtuais tornam a situação mais preocupante, pois expõem a fragilidade da leitura entre os alunos da EJA, não se materializando como ação praxiológica, mas como uma apropriação de conhecimentos de forma rudimentar, que pouco contribui para uma formação humana de fato emancipatória.

Artigo recebido em: 20/12/2017

Aprovado para publicação em: 22/03/2018

THE ACQUISITION OF READING BY STUDENTS OF THE EJA / MIDDLE SCHOOL IN POPULAR CONTEXTS

ABSTRACT: The present research seeks to approach ways of acquiring reading in peripheral spaces as a strategy for human education in youth and adult education (EJA). This work has as general objective to analyze ways of acquiring reading in the reality of EJA / EnsinoMédio students in the city of Macapá / Ap. We will use qualitative and quantitative approaches as well as graphs, with the application of questionnaires for 23 students. We conclude that most of the students do not recognize reading spaces as a community library, nor does the practice of reading as an instrument of educational 
/ human formation, divorcing the acquisition of the reading of the re-signification of the reality of the people and the community.

KEYWORDS: Community library. Reading practice. Youth and adult education. High school.

\section{LA ADQUISICIÓN DE LA LECTURA POR ALUMNOS DE LA EJA/ ENSEÑANZA MEDIO EN CONTEXTOS POPULARES}

RESUMEN: La presente investigación busca abordar formas de adquisición de la lectura en espacios periféricos como estrategia para la formación humana en la educación de jóvenes y adultos (EJA). Este trabajo tiene como objetivo general analizar formas de adquisición de la lectura en la realidad de alumnos de la EJA / Enseñanza Media en la ciudad de Macapá / Ap. Utilizaremos los enfoques cualitativos y cuantitativos, además de gráficos, con la aplicación de cuestionarios para 23 alumnos. Concluimos que la mayoría de los alumnos no reconoce los espacios de lectura como biblioteca comunitaria, tampoco la práctica de la lectura como instrumento de formación educativa / humana, divorciando la adquisición de la lectura de la resignificación de la realidad de las personas y de la comunidad.

Palabras clave: Biblioteca comunitaria. Práctica de lectura.Educación de jóvenes y adultos. Enseñanza Media.

\section{REFERÊNCIAS}

ANGÉLICO, F. Um orgulho raro. São Paulo: Agência Pública, 2012. Disponível em: http:// apublica.org/2012/07/serie-futuro-da-amazonia-parte-1/. Acesso em: 2 nov. 2016

. Corrupção e educação na Amazônia. São Paulo: Agência Pública, 2012. Disponível em: <http://apublica.org/2012/07/corrupcao-e-educacao-na-amazonia-2/>. Acesso em: 2 nov. 2016

ARROYO, M. Educação de jovens-adultos: um campo de direitos e de responsabilidade pública. In: GOMES, N. L.; SOARES, L.; GIOVANETTI, M. A. Diálogos na educação de jovens e adultos. 4. ed. Belo Horizonte: Autêntica Editora, 2011.

BRASIL. Lei n 9394/1996 - Lei de diretrizes e Bases da Educação Nacional. Brasília, 1996. . Atlas da Violência. Pesquisa Nacional de Amostragem de Domicílios (PNAD)/ Fórum Brasileiro de Segurança Pública, n 17. Brasília, março de 2016. Disponível em: <http://www.ipea.gov.br/portal/images/stories/PDFs/nota_tecnica/160322_nt_17_ atlas_da_violencia_2016_finalizado.pdf>. Acesso em: 22 dez. 2016. 
CACHAPUZ, A. Epistemologia e ensino das ciências no pós mudança conceptual: análise de um percurso de pesquisa In: ENCONTRO NACIONAL DE PESQUISA EM EDUCAÇÃO EM CIÊNCIAS, 2. Anais... Valinhos, São Paulo, 1999.

CIAVATA, M.; RUMMERT, S. M. As implicações políticas e pedagógicas do currículo na educação de jovens e adultos integrada à formação profissional. Educação \& Sociedade, Campinas, v. 31, n. 111, p. 461-480, abr./jun. 2010. Disponível em <http://www.cedes. unicamp.br>. Acesso em: maio 2016.

COELHO, C. D. Mediação e bibliotecas comunitárias: o papel do mediador no incentivo a leitura. In: SEMINÁRIO EM CIÊNCIA DA INFORMAÇÃO - FENÔMENOS EMERGENTES NA CIÊNCIA DA INFORMAÇÃO, 6. Londrina - PR, 3 a 5 ago. 2016, p. 417-428. Disponível em: <http://www.uel.br/eventos/cinf/index.php/secin2016secin2016/paper/viewFi le/291/149>. Acesso em: set. 2016.

FREIRE, P. Pedagogia do oprimido. 17 ed. Rio de Janeiro: Paz e Terra, 1987.

GRAMSCI, A. Os intelectuais e a organização da cultura. 7. ed.. Rio de Janeiro: Editora Civilização Brasileira, 1989.

HADDAD, S.; DI PIERRO, M. C. Aprendizagem de Jovens e Adultos: avaliação da década da educação para todos. Revista São Paulo em Perspectiva, São Paulo, p. 29-40, 2000.

JANTSCH, A. P. Concepção dialética de escrita e leitura: um ensaio. In: BIANCHETTI, Lucídio (Org.). Trama e texto: leitura crítica: escrita criativa. 2. ed. São Paulo: Summus, 2002. KOSIK, K. Dialética do concreto. Rio de Janeiro: Paz e Terra, 1976.

MACHADO, C.E; VERGUEIRO, W. Bibliotecas comunitárias como prática social no Brasil. CRB-8Digital, São Paulo, v. 3, n. 1, p. 3-11, ago. 2010. Disponível em: http://revista.crb8. org.br/index.php/crb8digital/article/view/44/45>. Acesso em: maio 2016.

MINAS GERAIS (Estado). Fórum Mineiro de Educação de Jovens e Adultos. Secretaria de Estado de Educação: Belo Horizonte (MG), 2010 Disponível em: < http://forumdasjuventudes.org.br/forum-mineiro-de-educacao-de-jovens-e-adultos-lanca-propostas-para-pautar-o-processo-eleitoral/>. Acesso em: maio 2016.

MINAYO, M. C. S. O desafio do conhecimento: pesquisa qualitativa em saúde. 10. ed. São Paulo: HUCITEC, 2007. 406 p.

RUMMERT, S. M. A educação de jovens e adultos trabalhadores brasileiros no século XXI. O"novo" que reitera antiga destituição de direitos. Sísifo, Revista de Ciência da Educação, v. 2, p. 35-50, 2007. Disponível em: http://sisifo.fpce.ul.pt. Acesso em: maio 2016.

Educação de jovens e adultos trabalhadores no Brasil atual: do simulacro à emancipação. Perspectiva, Florianópolis, v. 26, n. 1, p. 175-208, jan./jun. 2008. Disponível em: <http://www.uff.br/ejatrabalhadores/artigos/educacao-jovens-adultos-trabalhadores-brasil-atual.pdf>. Acesso em: maio 2016. 
SILVA, G. P.; RODRIGUES. D. S.; RODRIGUES, Doriedson S. Linguagem e educação na Amazônia: faces e interfaces de pesquisa. In: SILVA, G. P.; RODRIGUES. D. S. (Orgs.). Práticas de leitura e escrita. Cametá, PA: Editora EDUFPA, 2010. $3 \mathrm{v}$.

SILVA, R. P. A. Práticas de leitura e uso de sites de redes sociais entre estudantes de jornalismo, 2015. Disponível em: <http://portalintercom.org.br/anais/nacional2015/ re sumos/R10-1363-1.pdf >. Acesso em: ago.2016.

STRELHOW, T. B. Breve história sobre a educação de jovens e adultos no Brasil. Revista HISTEDBR, Campinas, n. 38, p. 49-59, jun. 2009. Disponível em: <http://www.histedbr. fe.unicamp.br/revista/edicoes/38/art05_38.pdf>. Acesso em: ago. 2016.

THIOLLENT, M. Crítica metodológica, investigação social e enquete operária. São Paulo: Polis, 1981.

JoÃo Paulo da Concelção Alves: Doutor em Educação pela UFPA. Professor Adjunto I na Universidade Federal do Amapá. Pesquisa nas áreas: Trabalho, Educação, Educação de Jovens e Adultos e Ensino Médio.

E-mail: jpaulochee@smail.com

Carla lorena Rodrigues de Carvalho: Especialista em Produção de Material Didático para EJA pela UNIFAP. Membro do Grupo de Pesquisa GEFOR, onde desenvolve pesquisas nas seguintes áreas: Trabalho, Educação, Leitura e Letramento, Educação de Jovens e Adultos e Ensino Médio.

E-mail: rcarvalho.mama@hotmail.com

MÁrcia Pereira da Silva: Especialista em Gestão Escolar Integrada e Práticas Pedagógicas pela Universidade Cândido Mendes (UCAM). Membro do Grupo de Pesquisa GEFOR, onde desenvolve pesquisas nas seguintes áreas: Trabalho, Educação, Relações étnico-raciais, Educação de Jovens e Adultos e Ensino Médio.

E-mail: marcinha_afro@hotmail.com 